\title{
CO Gas-Induced Resonance Frequency Shift of ZnO-Functionalized Microcantilever in Humid Air
}

\author{
Lia Aprilia, ${ }^{1,2,3}$ Ratno Nuryadi, ${ }^{1}$ Dwi Gustiono, ${ }^{1}$ Nurmahmudi, ${ }^{4}$ Arief Udhiarto, ${ }^{2}$ \\ Djoko Hartanto, ${ }^{2}$ Brian Yuliarto, ${ }^{5}$ Makoto Hosoda, ${ }^{3}$ Yoichiro Neo, ${ }^{3}$ and Hidenori Mimura ${ }^{3}$ \\ ${ }^{1}$ Center for Materials Technology, Agency for the Assessment and Application of Technology, Puspiptek Building No. 224, \\ South Tangerang, Banten 15314, Indonesia \\ ${ }^{2}$ Department of Electrical Engineering, Faculty of Engineering, Universitas Indonesia, Depok 16424, Indonesia \\ ${ }^{3}$ Research Institute of Electronics, Shizuoka University, 3-5-1 Johoku, Naka-ku, Hamamatsu, Shizuoka 432-8011, Japan \\ ${ }^{4}$ Center for Technology Strategy and Audit, Agency for the Assessment and Application of Technology, South Tangerang, \\ Banten, Indonesia \\ ${ }^{5}$ Engineering Physics Department, Institut Teknologi Bandung, Bandung 40132, Indonesia
}

Correspondence should be addressed to Ratno Nuryadi; ratno.nuryadi@bppt.go.id

Received 25 April 2017; Revised 6 July 2017; Accepted 3 August 2017; Published 10 September 2017

Academic Editor: Xiaowei He

Copyright (C) 2017 Lia Aprilia et al. This is an open access article distributed under the Creative Commons Attribution License, which permits unrestricted use, distribution, and reproduction in any medium, provided the original work is properly cited.

Resonance frequency shift of a zinc oxide- ( $\mathrm{ZnO}$-) functionalized microcantilever as a response to carbon monoxide (CO) gas has been investigated. Here, $\mathrm{ZnO}$ microrods were grown on the microcantilever surface by a hydrothermal method. The measurement of resonance frequency of the microcantilever vibrations due to the gas was carried out in two conditions, that is, gas flow with and without air pumping into an experiment chamber. The results show that the resonance frequency of the $\mathrm{ZnO}$-functionalized microcantilever decreases because of $\mathrm{CO}$ in air pumping condition, while it increases when $\mathrm{CO}$ is introduced without air pumping. Such change in the resonance frequency is influenced by water vapor condition, and a possible model based on water-CO combination was proposed.

\section{Introduction}

Microcantilever-based sensors could replace conventional sensors because of the ability to detect ultrasmall mass with fast response time. The working principle of this sensor is based on deflection of microcantilever (MC) due to an object attached on its surface (static mode) or resonance frequency shift of the MC vibration due to an object (dynamic mode). So far, the smallest mass detected using MC has been reported as femtogram $\left(10^{-15}\right.$ gram $)$ level by Sone et al. [1], attogram level $\left(10^{-18}\right.$ gram) [2], and zeptogram level $\left(10^{-20}\right.$ gram) by Roukes group [3].

On the other hand, in order to selectively detect chemical or biological molecules, a sensitive layer must be deposited on the microcantilever surface, such as polymer [4] and metal oxide sensitive layers [5]. In gas detection, several publications have shown that the resonance frequency of MC decreased due to exposure of the gas, such as mercury [6], volatile organic compounds [7], ethanol [8], carbon dioxide [9], freon [10], and water vapor [11]. However, for real sensor applications, the sensor response should be considered in various conditions, such as in higher humidity or vacuum conditions.

Generally, gas detection on metal oxide surfaces, such as zinc oxide $(\mathrm{ZnO})$ which has a great potential in sensing applications, is especially influenced by the presence of humidity [12]. In ambient condition, the surface is fully covered by molecularly adsorbed water [13]. Gouvea et al. reported that $\mathrm{CO}_{2}$ and $\mathrm{H}_{2} \mathrm{O}$ energetically had same possibility for binding to a $\mathrm{ZnO}$ surface [14]. Consequently, the water-CO combination should be considered as a model system for gas detection on metal oxide surfaces.

In this work, we have grown $\mathrm{ZnO}$ microrods on the microcantilever surface as sensitive layers for gas detection and studied the effect of carbon monoxide (CO) on resonance frequency of the $\mathrm{MC}$ at a room temperature. Here, we studied 


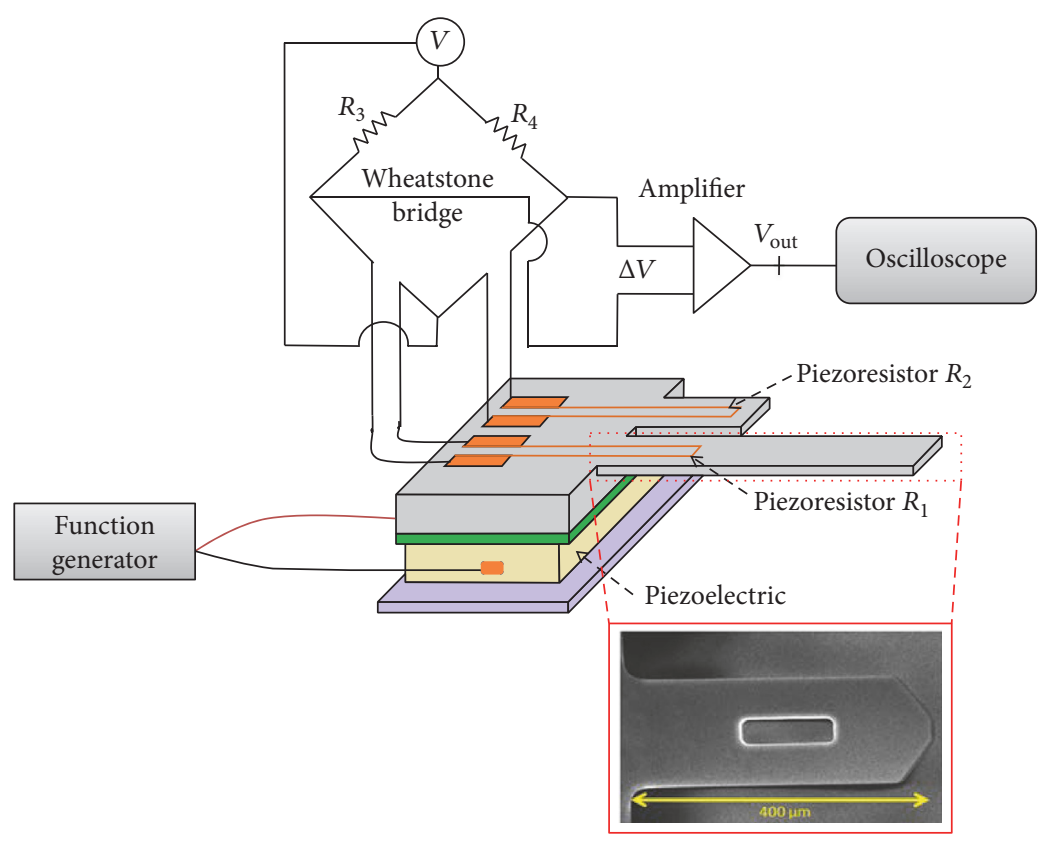

FIGURE 1: Schematic circuit system using piezoresistive microcantilever. The inset figure is a SEM image of the microcantilever.

the effect of $\mathrm{CO}$ in different conditions, that is, with and without air flow. We experimentally observed a decrease in the resonance frequency due to gas flow with air pumping and an increase in the resonance frequency without air pumping. The possible model is also proposed to explain the experimental results.

\section{Experimental Details}

2.1. $\mathrm{ZnO}$ Microrods Formation. Formation of the $\mathrm{ZnO}$ microrods consists of initial layer preparation and growth of rods. First, the MC was coated by an initial solution which was made of $0.3 \mathrm{M}$ diethanolamine in ethylene glycol and stirred at $75^{\circ} \mathrm{C}$ for 1 hour. The coated cantilever was annealed at $100^{\circ} \mathrm{C}$ for 30 minutes.

The $\mathrm{ZnO}$ was then grown on the cantilever surface by dipping it in $\mathrm{ZnO}$ solution at $90^{\circ} \mathrm{C}$ for 2 hours. Here, the $\mathrm{ZnO}$ solution was prepared by using $0.02 \mathrm{M}$ zinc nitrate tetrahydrate $\left(\mathrm{Zn}\left(\mathrm{NO}_{3}\right)_{2} \cdot 6 \mathrm{H}_{2} \mathrm{O}\right)$ and hexamethylenetetramine $\left(\mathrm{CH}_{2}\right)_{6} \mathrm{~N}_{4}$ in ethanol and aqua bidest (1:3). Hexamethylenetetramine acts as a $\mathrm{pH}$ buffer of the solution and supply of $\mathrm{OH}^{-}$ions, as seen in the following reaction equations:

$$
\begin{aligned}
\left(\mathrm{CH}_{2}\right)_{6} \mathrm{~N}_{4}+6 \mathrm{H}_{2} \mathrm{O} & \longrightarrow 6 \mathrm{HCHO}+4 \mathrm{NH}_{3} \\
\mathrm{NH}_{3}+\mathrm{H}_{2} \mathrm{O} & \longleftrightarrow \mathrm{NH}_{4}^{+}+\mathrm{OH}^{-} \\
\mathrm{Zn}^{2+}+2 \mathrm{OH}^{-} & \longrightarrow \mathrm{Zn}(\mathrm{OH})_{2} \\
\mathrm{Zn}(\mathrm{OH})_{2} & \stackrel{\Delta}{\longrightarrow} \mathrm{ZnO}+\mathrm{H}_{2} \mathrm{O}
\end{aligned}
$$

Precipitation of $\mathrm{ZnO}$ nuclei starts when the concentration of $\mathrm{Zn}^{2+}$ and $\mathrm{OH}^{-}$ions exceeds a critical value. Here, the $\mathrm{ZnO}$ nuclei are building blocks for the formation of the rods.
Thus, $\mathrm{Zn}(\mathrm{OH})_{2}$ can be transformed into $\mathrm{ZnO}$ crystals with hexagonal shape due to the crystal habits of $\mathrm{ZnO}$. As a result, $\mathrm{ZnO}$ microrods are grown. Finally, the $\mathrm{ZnO}$-microrodscoated MC is dried at $80^{\circ} \mathrm{C}$ for 1 hour. To confirm the growth of $\mathrm{ZnO}$, we performed energy dispersive spectroscopy (EDS) analysis and scanning electron microscopy (SEM) on the MC surface.

2.2. Electronic Circuit. In this work, a commercial piezoresistive microcantilever (Seiko Instruments Inc.) was used, as shown in Figure 1. A long MC (see an inserted SEM image in Figure 1) has a length of $400 \mu \mathrm{m}$, a width of $50 \mu \mathrm{m}$, spring constant $(k)$ of $4 \mathrm{~N} / \mathrm{m}$, and piezoresistor $R_{1}$ of about $630 \Omega$ [1]. A short cantilever with piezoresistor $R_{2}$ (about $630 \Omega$ ) is a reference cantilever, which is crucial in order to reduce background noise, such as thermal drift and gas turbulence [15]. In the piezoresistive microcantilever, the deflection of it produces a resistivity change of the piezoresistor. Such resistivity change was measured by using a Wheatstone bridge, which is constructed by two piezoresistors in the $\mathrm{MC}\left(R_{1}\right.$ and $\left.R_{2}\right)$ and two external resistors $\left(R_{3}\right.$ and $\left.R_{4}\right)$, as schematically shown in Figure 1.

Output of Wheatstone bridge $(\Delta V)$ in Figure 1 could be written as $\Delta V=\left(R_{1} R_{3}-R_{2} R_{4}\right) V /\left(R_{1}+R_{2}\right)\left(R_{3}+R_{4}\right)$. The output $\Delta V$ is varied when the value of piezoresistor $R_{1}$ changes during gas detection. $\Delta V$ is then amplified resulting in $V_{\text {out }}$, which is monitored with an oscilloscope. In order to actuate the MC in dynamic mode operation, a function generator is used for applying a sinusoidal wave to piezoelectric element.

2.3. Carbon Monoxide Gas Measurement. When the actuated microcantilever vibrates in a certain frequency, we measured the resonance frequency of the MC vibration before and 


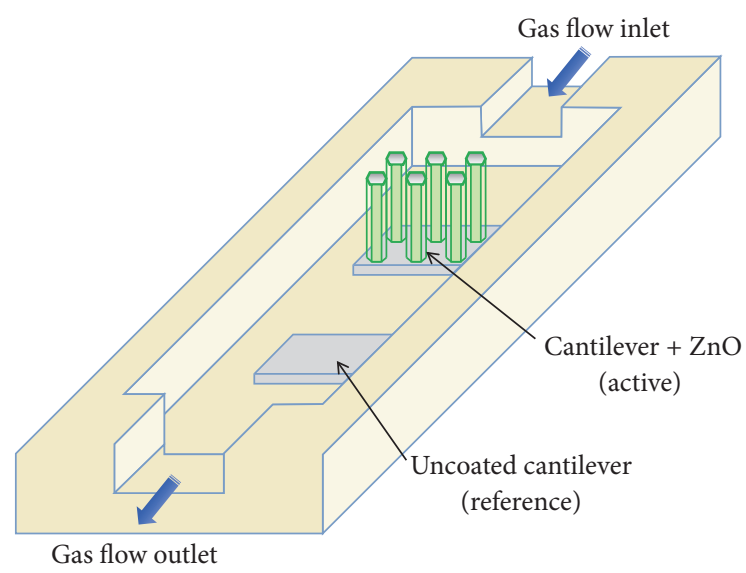

FIGURE 2: Schematic view of chamber for gas measurement.

after gas detection. In gas measurements, we first put two cantilevers inside the chamber, as shown in Figure 2. The first cantilever was coated by $\mathrm{ZnO}$ microrods (active cantilever), while the second one was an uncoated reference cantilever. We conducted the measurement at room temperature. First, carbon monoxide gas was introduced into the chamber at various concentrations, that is, $30 \mathrm{ppm}, 70 \mathrm{ppm}$, and $100 \mathrm{ppm}$. Then air was pumped to the chamber by using an air compressor. The resonance frequency shifts for each gas concentration were measured by using an oscilloscope. Second, carbon monoxide gas was introduced into the chamber at a flow rate of $1 \mathrm{ml} / \mathrm{min}$ at $25^{\circ} \mathrm{C}$ and relative humidity of $65 \% \mathrm{RH}$. Here, the gas was inserted (gas ON) and turned off (gas OFF) until stable condition was reached. Then, change of the resonance frequency as a function of time was monitored by using the oscilloscope. We should note that, in contrast to the first condition, air was not pumped into the chamber during gas OFF condition.

\section{Results and Discussions}

3.1. Characterization of Zinc Oxide Rods. ZnO microrods were successfully grown on silicon microcantilevers as a sensitive layer. Figure 3 shows a SEM image of them deposited on the MC surface forming a flower-like $\mathrm{ZnO}$ structure. Even though the formed rods are not well aligned, we can see the hexagonal shape of the rods. It is predicted that the crystal structure of $\mathrm{ZnO}$ fabricated in this way is hexagonal wurtzite. The length and diameter of $\mathrm{ZnO}$ microrods are approximately $6 \mu \mathrm{m}$ and $1 \mu \mathrm{m}$, respectively. These microstructures have a virtue of large surface area to adsorb gas molecules.

Next, the chemical composition of the $\mathrm{ZnO}$ microrods was characterized by EDS. Table 1 shows EDS result for the "A" point of the rod deposited on a silicon MC surface (see Figure 3). The elements of $\mathrm{Zn}$ and $\mathrm{O}$ refer to $\mathrm{ZnO}$ composition with ratio $1.6: 1$, which indicate the presence of defects of interstitial $\mathrm{Zn}$ or deficiency of the oxygen. Oxygen vacancies in $\mathrm{ZnO}$ are attributed to donor type defects contributing $n$-type conductivity of the material. The element $\mathrm{Si}$ comes from silicon material of the microcantilever, while the element $\mathrm{Au}$ is originated from residual conductive

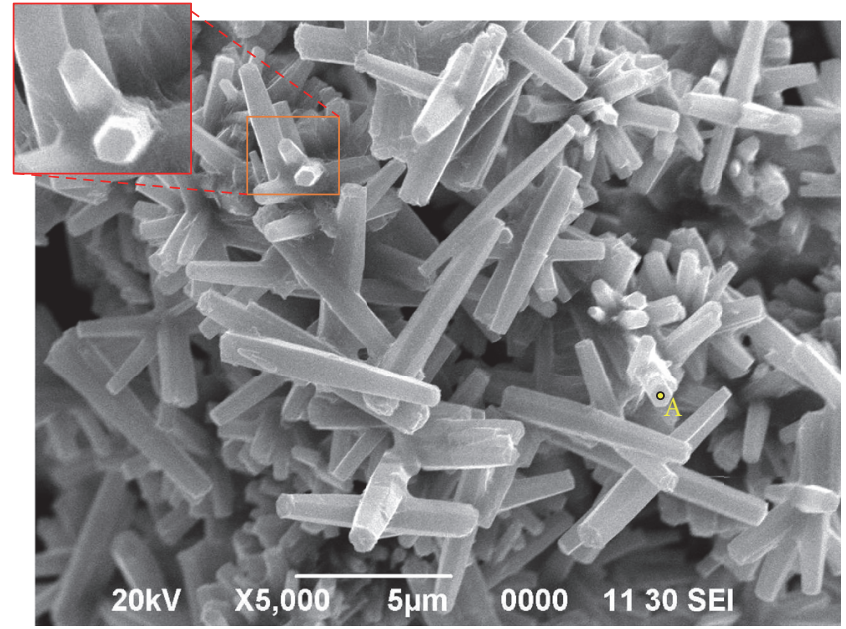

FIGURE 3: Scanning electron micrograph of $\mathrm{ZnO}$ sensitive layer. The inset is a zoomed-in image of hexagonal shape of $\mathrm{ZnO}$. The yellow character "A" indicates EDS sensing position.

TABLE 1: Energy dispersive spectroscopy (EDS) result for $\mathrm{ZnO}$.

\begin{tabular}{lccc}
\hline Element & Mass\% & Error\% & Atom\% \\
\hline $\mathrm{O}$ & 12.29 & 0.31 & 36.43 \\
$\mathrm{Si}$ & 2.65 & 0.35 & 4.48 \\
$\mathrm{Zn}$ & 79.63 & 1.54 & 57.78 \\
$\mathrm{Au}$ & 5.43 & 1.04 & 1.31 \\
\hline Total & 100.00 & & 100.00 \\
\hline
\end{tabular}

material during SEM preparation. Even though the ratio of $\mathrm{Zn}$ and $\mathrm{O}$ is not equal to $1: 1$, the EDS result clearly shows that the rods formed on the MC surface are pure $\mathrm{ZnO}$.

\subsection{Resonance Frequency Shift due to Gas Adsorption}

3.2.1. Various CO Concentrations during Air Pump Treatment. The initial frequencies of both microcantilevers were measured before measurement. The initial resonance frequency ( $f$ ) of the active cantilever was $29.060 \mathrm{kHz}$, while the frequency of reference cantilever was $40.340 \mathrm{kHz}$. Note that the resonance frequency of the active cantilever before $\mathrm{ZnO}$ coating was about $40 \mathrm{kHz}$. The decrease in its resonance frequency $(\Delta f \sim 10 \mathrm{kHz})$ is caused by $\mathrm{ZnO}$ microrods formation.

$\mathrm{CO}$ at concentrations of $30 \mathrm{ppm}, 70 \mathrm{ppm}$, and $100 \mathrm{ppm}$ was then introduced and ambient air was pumped into the chamber by using an air compressor pump before and after introducing the gas. The effect of $\mathrm{CO}$ at various concentrations is shown in Figure 4. First, $30 \mathrm{ppm} \mathrm{CO}$ gas was introduced into the chamber, resulting in decrease of the resonance frequency of the active cantilever (blue marker) to $28.880 \mathrm{kHz}$. After stabilizing, the gas flow was stopped and air was pumped into the chamber. As a result, the resonance frequency increased to $29.050 \mathrm{kHz}$. Such resonance frequency shift $(\Delta f)$ of $180 \mathrm{~Hz}$ is a function of a mass change $(\Delta m)$ due to adsorbed gas on the $\mathrm{ZnO}$ surface which can be calculated using (5) and (6) [1]. It is noted that decrease in 


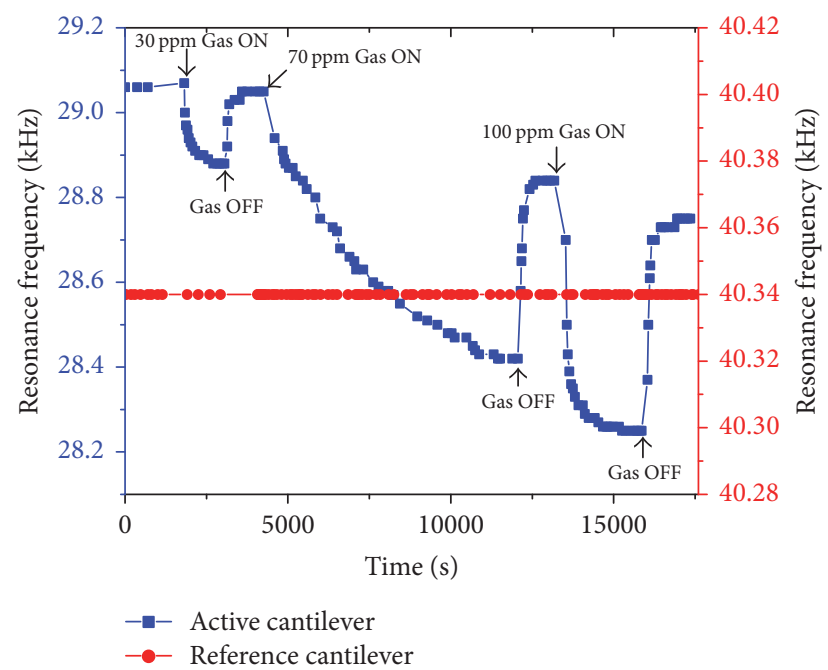

FIGURE 4: Resonance frequency as a function of time for both microcantilevers (active cantilever: blue square markers for left axis, and reference cantilever: red circle markers for right axis) exposed to carbon monoxide gas in constant flow.

Q-factor [16] of $\mathrm{ZnO}$-coated $\mathrm{MC}$ occurs when the gas was introduced ( $\Delta Q \sim 1$ due to $1 \mathrm{ml} / \mathrm{min}$ flow of $\mathrm{CO}$ ), but such small change of $Q$-factor does not affect the measurement of resonance frequency shift. Our results about a decrease and an increase in resonance frequency due to gas $\mathrm{ON}$ and OFF are consistent with previous reports of the microcantileverbased gas detection [7-10].

From (5), the mass of the $\mathrm{ZnO}$-coated $\mathrm{MC}(\mathrm{m})$ is determined to be 120 picograms, and using (6), the absorbed molecules on the $\mathrm{ZnO}$ layer are calculated to be 2.56 picograms. So the sensor sensitivity for carbon monoxide detection is about 8.27 femtogram $/ \mathrm{Hz}$.

$$
\begin{aligned}
m & =\frac{k}{(2 \pi f)^{2}}, \\
\Delta m & =-2 \frac{m}{f} \Delta f .
\end{aligned}
$$

Next, 70 ppm CO was inserted and the resonance frequency decreased to $28.420 \mathrm{kHz}$. The longer response time for reaching a stable state may be due to air humidity change during this measurement. When the gas was turned off and the air compressor was turned on, the resonance frequency of the MC increased to $28.840 \mathrm{kHz}$. Finally, the MC was exposed to $100 \mathrm{ppm} \mathrm{CO}$. The resonance frequency shifted to $28.250 \mathrm{kHz}$ and then increased to be $28.750 \mathrm{kHz}$ due to gas $\mathrm{OFF}$ and air flow. The difference of $310 \mathrm{~Hz}$ in the resonance frequency between initial resonance frequency $(29.060 \mathrm{kHz})$ and frequency after the gas measurement $(28.750 \mathrm{kHz})$ is probably caused by remaining gas molecules of about $1.49 \mathrm{fg}$ on the zinc oxide layer. Such difference was also found for gas concentrations of $30 \mathrm{ppm}$ and $70 \mathrm{ppm}$. It is noted that the resonance frequency of the reference cantilever (red marker) was almost constant during the measurement. We previously found that the water vapor was directly adsorbed on the uncoated $\mathrm{MC}$ which reduced the resonance frequency of $\mathrm{MC}$ [11]. However, in this work, the gas or water vapor may be adsorbed on the uncoated MC surface generating a change in its resonance frequency of less than $10 \mathrm{~Hz}$. As a result, the frequency shift at the graph almost disappeared. Therefore, it is convincing that the $\mathrm{ZnO}$ microrods play the role of the sensitive layer for response to gas.

Figure 4 also shows that the resonance frequency shift of the $\mathrm{ZnO}$-coated $\mathrm{MC}$ increases with increasing concentration of $\mathrm{CO}$, which is plotted in Figure 5. Such frequency shift depends on the number of $\mathrm{CO}$ molecules adsorbed on the $\mathrm{ZnO}$ surface. Therefore, the higher gas concentration results in larger resonance frequency shift. In Figure 5, the mass change of each concentration is calculated according to (6).

The decrease of the active resonance frequency due to $\mathrm{CO}$ can be probably explained as follows. Mostly, metal oxides adsorb water vapor molecules at their surface in ambient air. In the present experiment, air pumping treatment provides water vapor spreading inside the experiment chamber. Water molecules in air are likely to be dissociated on the $\mathrm{ZnO}$ surface into $\mathrm{OH}^{-}$and $\mathrm{H}^{+}$. Such water dissociation on $\mathrm{ZnO}$ surface into $\mathrm{OH}^{-}$and $\mathrm{H}^{+}$may produce the hydrogen-rich condition of the hydrogen ion, as discussed by $\mathrm{Xu}$ et al. [12]. Air pumping treatment generates a large amount of water vapor inside the chamber resulting in more dissociated hydrogen ion (hydrogen-rich) and vice versa. Under hydrogen-rich conditions, all $\mathrm{ZnO}$ surfaces have low formation energies [12] so that it would be easier to bind other molecules, such as CO molecules. Due to the presence of $\mathrm{CO}$, the gas molecules are physically adsorbed on $\mathrm{ZnO}$ surface through the dissociated water molecules (illustrated in Figure 6), resulting in the increase in the effective mass of the cantilever. Such increased mass generates the decrease in resonance frequency of the microcantilever.

3.2.2. Constant Flow of CO Gas without Air Pump Treatment. In this experiment, the $\mathrm{CO}$ gas was introduced into the chamber at a constant rate of $1 \mathrm{ml} / \mathrm{min}$ at humidity of $65 \%$ $\mathrm{RH}$, and then the gas was turned off without air pump until reaching a stable frequency. The initial resonance frequency $(f)$ of the active cantilever was $28.026 \mathrm{kHz}$, while the frequency of reference cantilever was $40.351 \mathrm{kHz}$. When gas flow was switched $\mathrm{ON}$ and $\mathrm{OFF}$, the resonance frequency of both cantilevers was measured and the frequency shift was investigated. The resonance frequency change of both microcantilevers due to $\mathrm{CO}$ can be seen in Figure 7. In contrast to the previous result in Figure 4, the resonance frequency of active MC increased due to gas exposure without air pump treatment. In order to explain this result, we firstly calculate the concentration of $\mathrm{CO}\left(C_{\mathrm{CO}}\right)$ in the chamber at stable condition using the following equation [17]:

$$
\begin{aligned}
& C_{\mathrm{CO}} \\
& =\frac{V_{\mathrm{CO}} \rho_{\mathrm{CO}}}{V_{\mathrm{ch}}\left(\mathrm{Mr}_{\mathrm{CO}} / 22.4\right)(273 /(273+T))(P / 101325)} \text { in } \mathrm{ppm},
\end{aligned}
$$

where $V_{\mathrm{CO}}$ is the sample volume of $\mathrm{CO}$ in $\mathrm{m}^{3}, \rho_{\mathrm{CO}}$ is relative density $\left(\mathrm{g} / \mathrm{m}^{3}\right), V_{\text {ch }}$ is the chamber volume in $\mathrm{m}^{3}, \mathrm{Mr}_{\mathrm{CO}}$ is the molar mass of the $\mathrm{CO}(\mathrm{g} / \mathrm{mol}), T$ is temperature in Kelvin, 


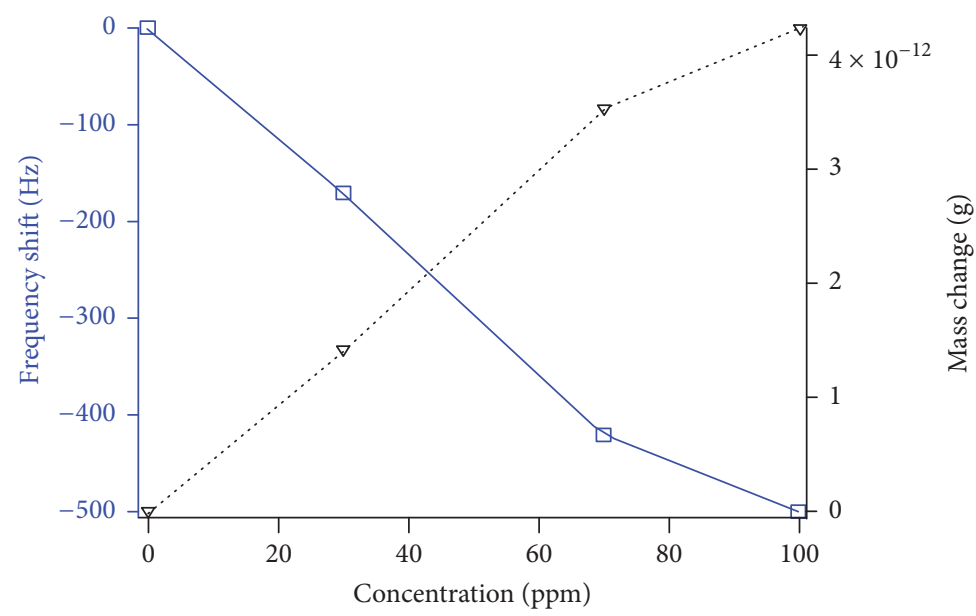

FIGURE 5: Resonance frequency shift (blue solid curve for left axis) and mass change (black dotted curve for right axis) versus CO concentration with average sensitivity of 8.27 femtogram $/ \mathrm{Hz}$.

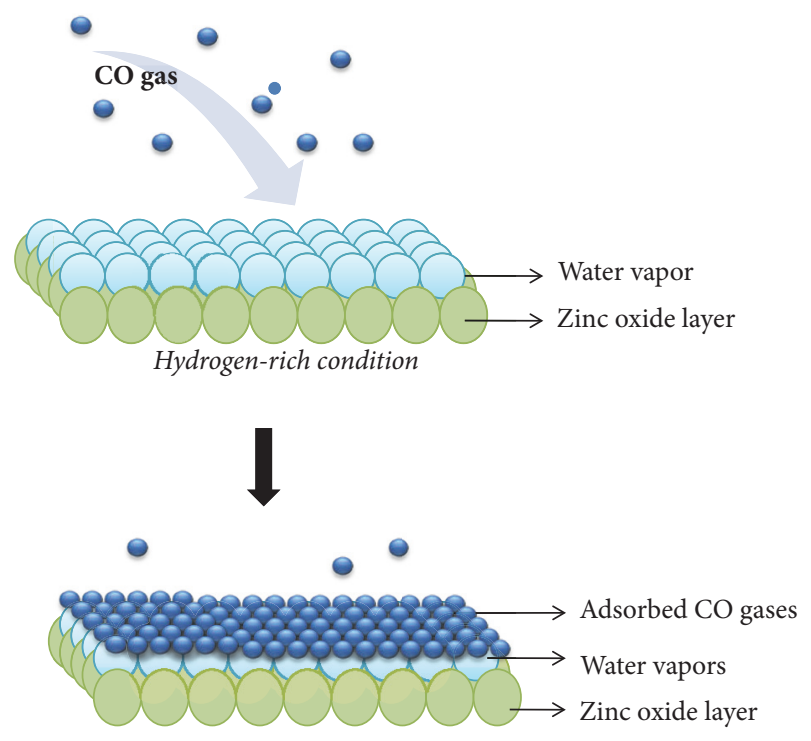

FIGURE 6: Possible model of CO gas adsorption in the presence of water vapors.

and $P$ is pressure in Pascal. In this calculation, we choose the condition at $611 \mathrm{~s}$ in Figure 7 where the resonance frequency saturated at $f \sim 29.18 \mathrm{kHz}$ after resonance frequency change due to $\mathrm{CO}$, and $V_{\mathrm{CO}}=0.01018 \mathrm{~m}^{3}, \rho_{\mathrm{CO}}=1.14 \mathrm{~kg} / \mathrm{m}^{3}$, $V_{\mathrm{ch}}=8 \times 10^{-5} \mathrm{~m}^{3}, \mathrm{Mr}_{\mathrm{CO}}=28 \mathrm{~g} / \mathrm{mol}, T=275 \mathrm{~K}$, and $P=101.325 \mathrm{kPa}$. We obtained that the $\mathrm{CO}$ concentration inside the chamber at the resonance frequency shift of $\Delta f \sim$ $1.16 \mathrm{kHz}$ is approximately $126.68 \mathrm{ppm}$.

Next, the CO gas flow was turned off, resulting in a decrease in the resonance frequency of active MC (blue marker) to be $28.506 \mathrm{kHz}$. This frequency did not return back to its initial value. As the gas flow was turned on, the resonance frequency of the active cantilever increased again to $29.276 \mathrm{kHz}$ with the resonance frequency shift of $0.77 \mathrm{kHz}$, and the frequency decreased to $28.316 \mathrm{kHz}$ due

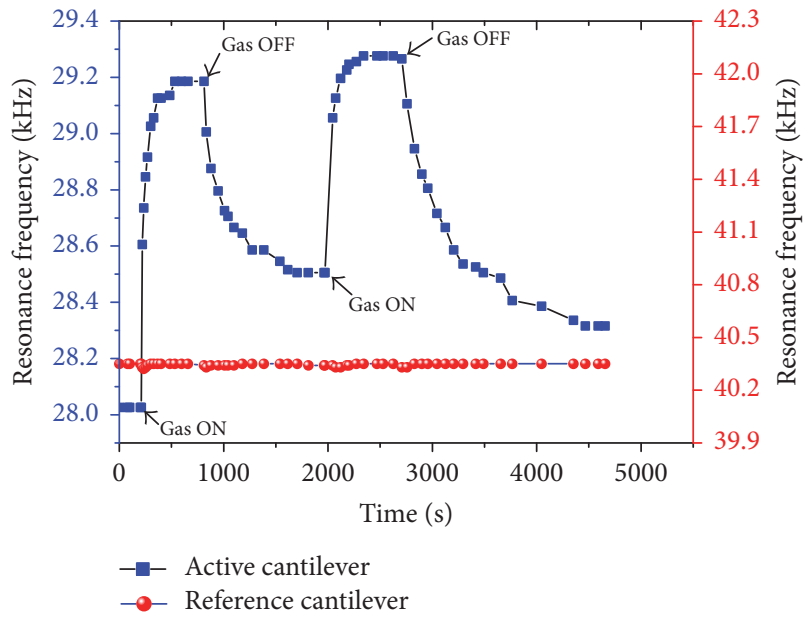

FIGURE 7: Resonance frequency versus time for both microcantilevers exposure to carbon monoxide gas without air pump treatment (active cantilever: blue square markers for left axis; reference cantilever: red circle markers for right axis).

to gas flow being turned off. As shown in Figure 4, the resonance frequency of reference $\mathrm{MC}$ (red marker) is also almost unchanged during the measurement.

Unlike the gas measurement with air pump treatment, the resonance frequency of the active $\mathrm{MC}$ increases due to effect of CO. The possible mechanism of this result may be due to the influence of water vapor which is explained in Figure 8. In high humidity, water vapor is adsorbed and dissociated on zinc oxide layer. In this experiment, the air pump treatment was not performed, resulting in hydrogen-poor condition on $\mathrm{ZnO}$ surface. Therefore, the structures with more dissociated water vapor on the $\mathrm{ZnO}$ surface become unstable. As a result, when $\mathrm{CO}$ is inserted into the chamber, the dissociated water vapor is desorbed from the $\mathrm{ZnO}$ surface and $\mathrm{CO}$ is directly adsorbed on the $\mathrm{ZnO}$ layer. Due to the lighter mass of $\mathrm{CO}$ gas layer, the resonance frequency of the active MC increases. 


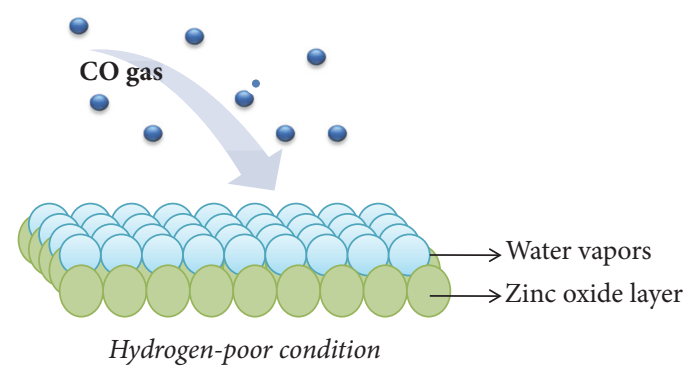

(a)

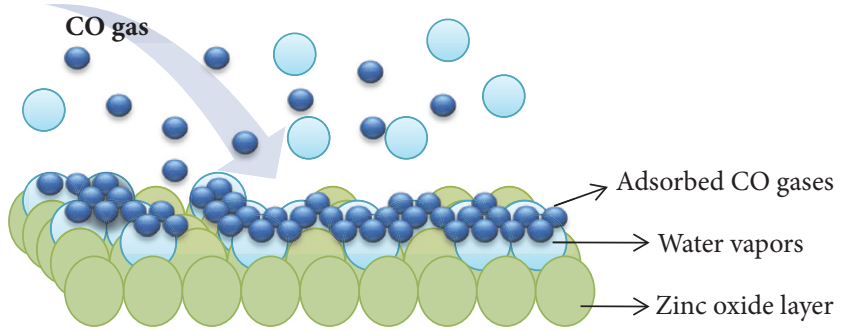

(b)

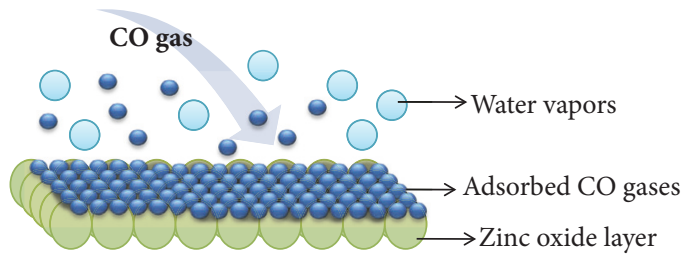

(c)

Figure 8: Possible model of $\mathrm{CO}$ gas adsorption in high humidity condition: (a) water vapors are present on the $\mathrm{ZnO}$ surface when $\mathrm{CO}$ is introduced; (b) CO gases produce the water vapor adsorption; (c) CO gases bind directly with zinc oxide layer.

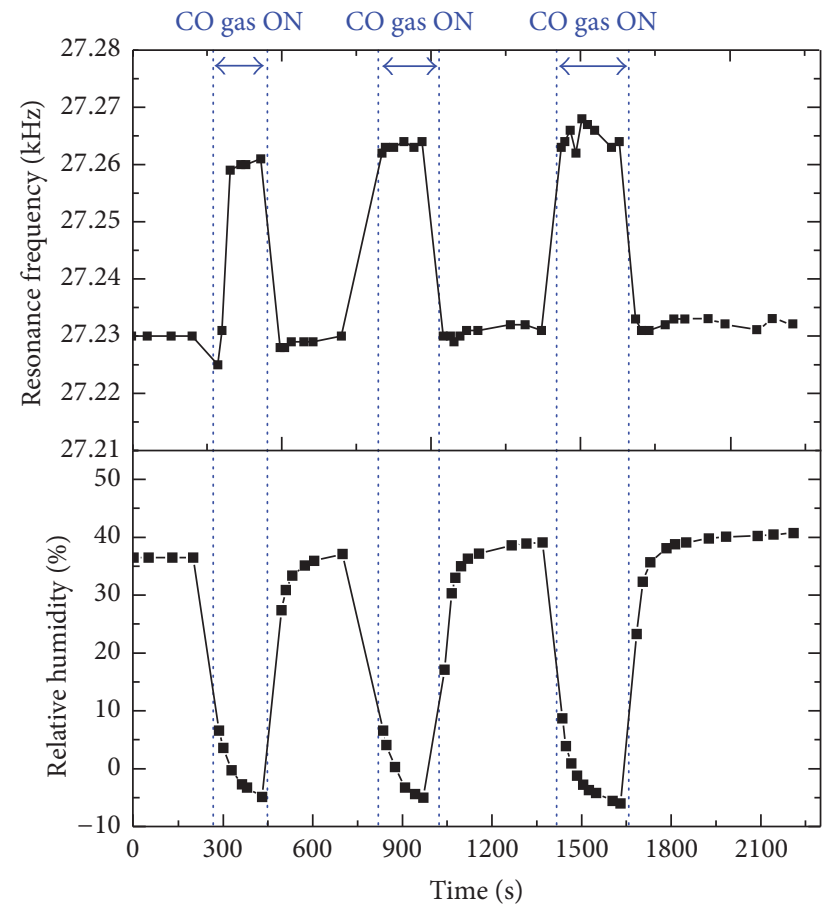

Figure 9: Relative humidity change due to introduced $\mathrm{CO}$ gas compared to resonance frequency change of the $\mathrm{ZnO}$-coated $\mathrm{MC}$.

Here, the resonance frequency does not return to an initial value after gas OFF because of limitation of the water vapor molecules inside the chamber.

To support the possible model in Figure 8, relative humidity $(\mathrm{RH})$ was changed while $\mathrm{CO}$ was inserted, as shown in Figure 9. Before introducing CO, the resonance frequency of active cantilever, relative humidity, and temperature were measured to be $27.230 \mathrm{kHz}, 36.5 \%$, and $19.4^{\circ} \mathrm{C}$, respectively.
When CO was inserted, the relative humidity decreased. We should note that the minus $\mathrm{RH}$ might be originated from sensor's offset error, where the conventional sensor is used in $1 \mathrm{~atm}$ air condition. The sensing condition at minus $\mathrm{RH}$ is different; that is, ambient gas contains CO gas (not pure air). However, the tendency of the RH changes reflects the humidity change. And intervals showing approximately $+35 \%$ RH in Figure 9 are measured under pure air conditions. Therefore, decrease in the $\mathrm{RH}$ data during insertion of $\mathrm{CO}$ exhibited a certain change in the humidity. Such results assumed that water vapor was desorbed from the $\mathrm{ZnO}$ surface and $\mathrm{CO}$ was adsorbed on the surface. This alteration results in an increase on the resonance frequency of the active microcantilever. As $\mathrm{CO}$ was switched off, relative humidity increased. Probably, $\mathrm{CO}$ was desorbed from the $\mathrm{ZnO}$ surface and replaced by water vapor, resulting in a decrease of the resonance frequency. The measurement was repeated three times with similar results. These results show that the model on Figure 8 can explain the increase of resonance frequency for the active cantilever due to $\mathrm{CO}$ exposure.

In this study, the measurements were done in humid air at room temperature. Therefore, the mechanisms proposed above may not be appropriate for high temperature. If the substrate temperature is raised, the water vapors at the $\mathrm{ZnO}$ surface evaporate. In this case, $\mathrm{CO}$ will be directly absorbed on the $\mathrm{ZnO}$ surface, resulting in a decrease in the resonance frequency of the active MC. The same condition occurs if the $\mathrm{ZnO}$ surface is modified with a hydrophobic coating, in which the water vapor should not be adsorbed on the $\mathrm{ZnO}$ surface, and in case of $\mathrm{CO}$ adsorption, the gas will be adsorbed on the hydrophobic layer.

\section{Conclusions}

We have grown $\mathrm{ZnO}$ microrods on MC surfaces and studied the gas response to the $\mathrm{ZnO}$ rods in humid air at room 
temperature. The results showed that the resonance frequency of the $\mathrm{ZnO}-\mathrm{MC}$ changed due to interaction with $\mathrm{CO}$. It was found that the sensitivity for $\mathrm{CO}$ detection was about 8 femtogram $/ \mathrm{Hz}$. However, the response is highly influenced by the presence of humidity. The resonance frequency of the $\mathrm{ZnO}-\mathrm{MC}$ decreased due to $\mathrm{CO}$ in rich water vapor condition, while the resonance frequency increased when $\mathrm{CO}$ was introduced in poor water vapor. We proposed the water$\mathrm{CO}$ combination-based model to explain the results.

\section{Conflicts of Interest}

The authors declare that they have no conflicts of interest.

\section{Acknowledgments}

This paper was funded by an incentive research grant from Ministry of Research, Technology and Higher Education of the Republic of Indonesia which the authors gratefully acknowledge.

\section{References}

[1] H. Sone, A. Ikeuchi, T. Izumi, H. Okano, and S. Hosaka, "Femtogram mass biosensor using self-sensing cantilever for allergy check," Japanese Journal of Applied Physics, Part 1: Regular Papers and Short Notes and Review Papers, vol. 45, no. 3B, pp. 2301-2304, 2006.

[2] M. Li, H. X. Tang, and M. L. Roukes, "Ultra-sensitive NEMSbased cantilevers for sensing, scanned probe and very highfrequency applications," Nature Nanotechnology, vol. 2, no. 2, pp. 114-120, 2007.

[3] Y. T. Yang, C. Callegari, X. L. Feng, K. L. Ekinci, and M. L. Roukes, "Zeptogram-scale nanomechanical mass sensing," Nano Letters, vol. 6, no. 4, pp. 583-586, 2006.

[4] C. Steffens, F. L. Leite, A. Manzoli, R. D. Sandoval, O. Fatibello, and P. S. P. Herrmann, "Microcantilever sensors coated with a sensitive polyaniline layer for detecting volatile organic compounds," Journal of Nanoscience and Nanotechnology, vol. 14, no. 9, pp. 6718-6722, 2014.

[5] N. Kilinc, O. Cakmak, A. Kosemen et al., "Fabrication of 1D $\mathrm{ZnO}$ nanostructures on MEMS cantilever for VOC sensor application," Sensors and Actuators, B: Chemical, vol. 202, pp. 357-364, 2014.

[6] T. Thundat, E. A. Wachter, S. L. Sharp, and R. J. Warmack, "Detection of mercury vapor using resonating microcantilevers," Applied Physics Letters, vol. 66, pp. 1695-1697, 1995.

[7] L. Guan, J. Zhao, S. Yu, P. Li, and Z. You, "Investigation of the frequency shift of a SAD circuit loop and the internal microcantilever in a gas sensor," Sensors, vol. 10, no. 7, pp. 7044-7056, 2010.

[8] L. Fadel, F. Lochen, I. Dufour, and O. Français, "Chemical sensing: Millimeter size resonant microcantilever performance," Journal of Micromechanics and Microengineering, vol. 14, no. 9, pp. S23-S30, 2004.

[9] C. Yim, M. Lee, M. Yun, G. Kim, K. T. Kim, and S. Jeon, " $\mathrm{CO}_{2}{ }^{-}$ Selective Nanoporous Metal-Organic Framework Microcantilevers," Scientific Reports, vol. 5, no. 1, 2015.

[10] J. Zhou, P. Li, S. Zhang et al., "Zeolite-modified microcantilever gas sensor for indoor air quality control," Sensors and Actuators, B: Chemical, vol. 94, no. 3, pp. 337-342, 2003.
[11] R. Nuryadi, A. Djajadi, R. Adiel, L. Aprilia, and N. Aisah, "Resonance frequency change in microcantilever-based sensor due to humidity variation," Materials Science Forum, vol. 737, pp. 176182, 2013.

[12] H. Xu, W. Fan, A. L. Rosa, R. Q. Zhang, and T. Frauenheim, "Hydrogen and oxygen adsorption on $\mathrm{ZnO}$ nanowires: a firstprinciples study," Physical Review B, vol. 79, no. 7, 2009.

[13] P. M. Kowalski, B. Meyer, and D. Marx, "Composition, structure, and stability of the rutile $\mathrm{TiO}_{2}(110)$ surface: Oxygen depletion, hydroxylation, hydrogen migration, and water adsorption," Physical Review B - Condensed Matter and Materials Physics, vol. 79, no. 11, Article ID 115410, 2009.

[14] D. Gouvêa, S. V. Ushakov, and A. Navrotsky, "Energetics of $\mathrm{CO}_{2}$ and $\mathrm{H}_{2} \mathrm{O}$ adsorption on zinc oxide," Langmuir, vol. 30, no. 30, pp. 9091-9097, 2014.

[15] H. P. Lang, R. Berger, F. Battiston et al., "A chemical sensor based on amicromechanical cantilever array for the identification of gases and vapors," Applied Physics A: Materials Science and Processing, vol. 66, no. 1, pp. S61-S64, 1998.

[16] A. Phani, V. Putkaradze, J. E. Hawk, K. Prashanthi, and T. Thundat, "A nanostructured surface increases friction exponentially at the solid-gas interface," Scientific Reports, vol. 6, Article ID 32996, 2016.

[17] Y. Dong, W. Gao, Q. Zhou, Y. Zheng, and Z. You, "Characterization of the gas sensors based on polymer-coated resonant microcantilevers for the detection of volatile organic compounds," Analytica Chimica Acta, vol. 671, no. 1-2, pp. 85-91, 2010. 

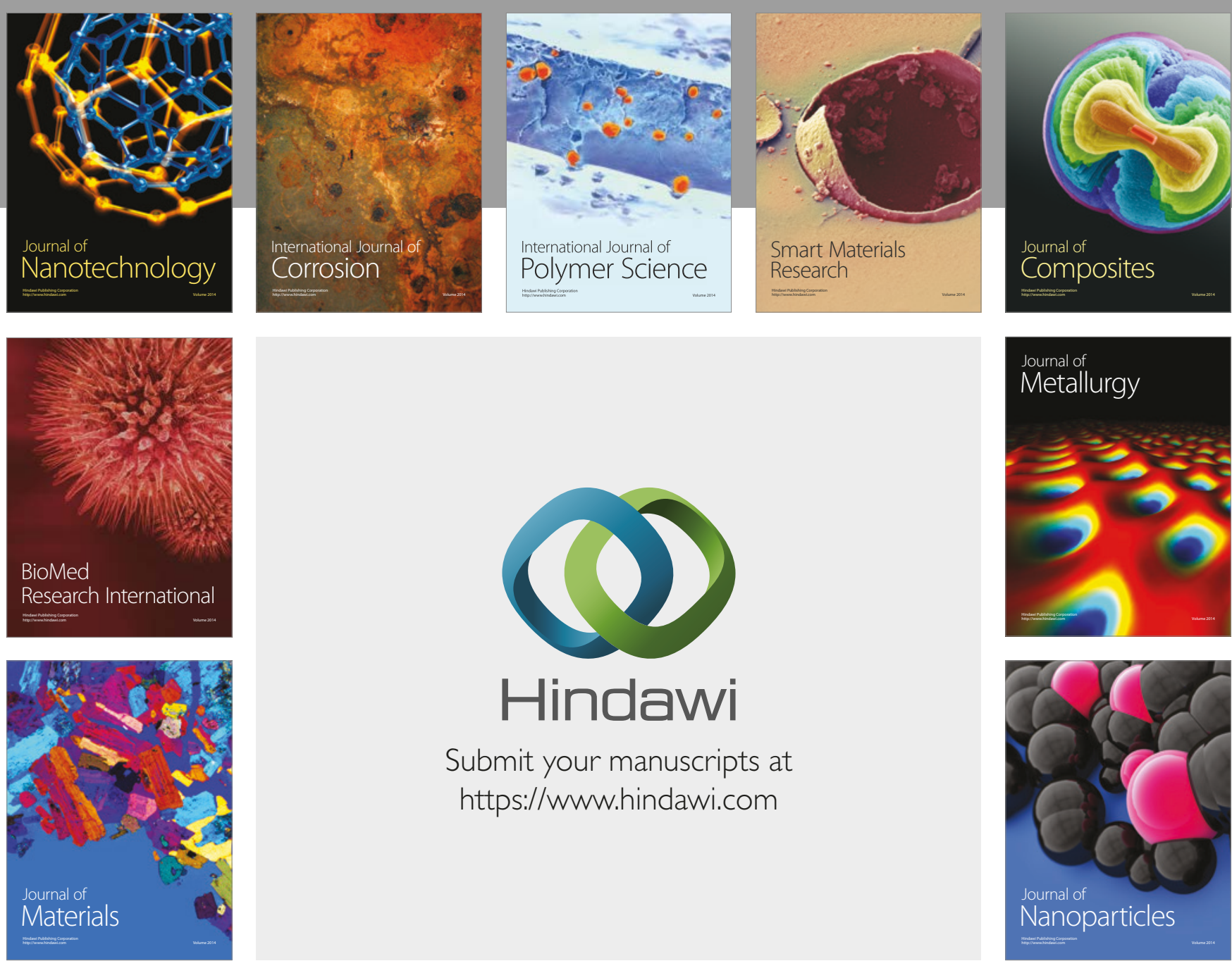

\section{Hindawi}

Submit your manuscripts at

https://www.hindawi.com
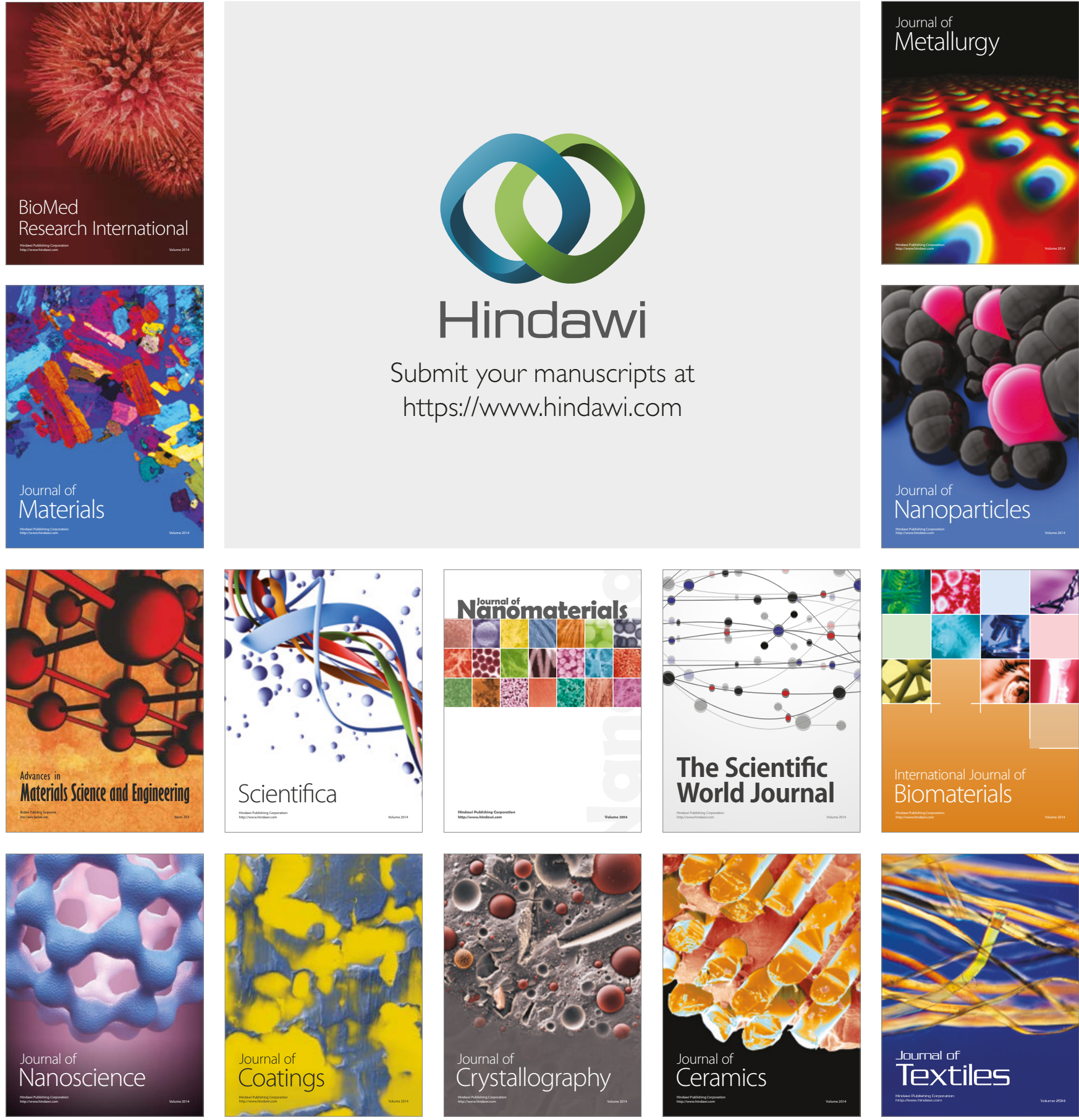

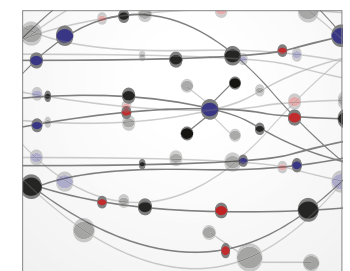

The Scientific World Journal
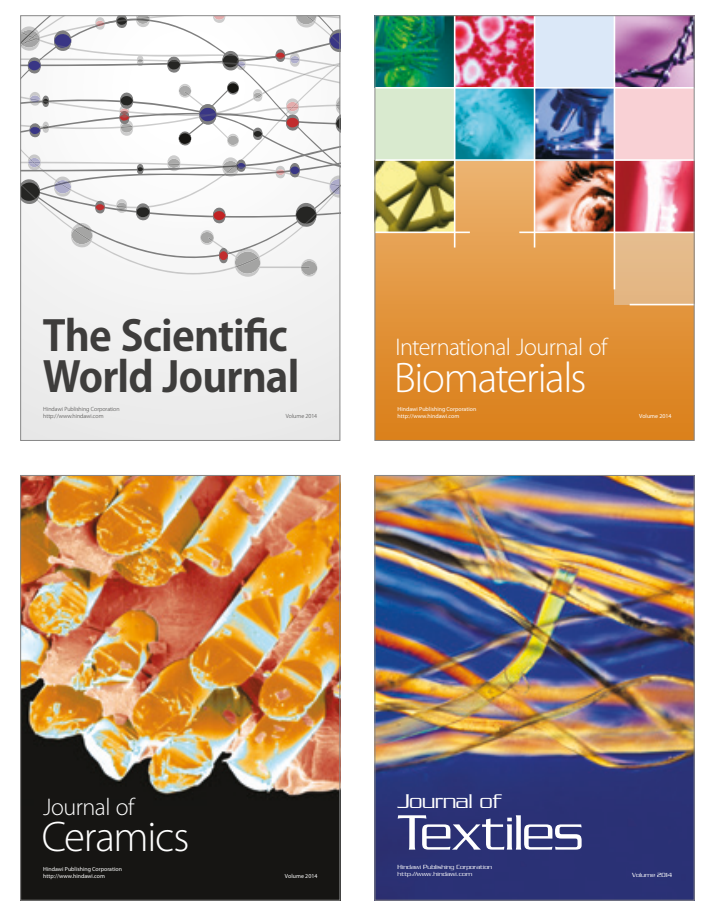